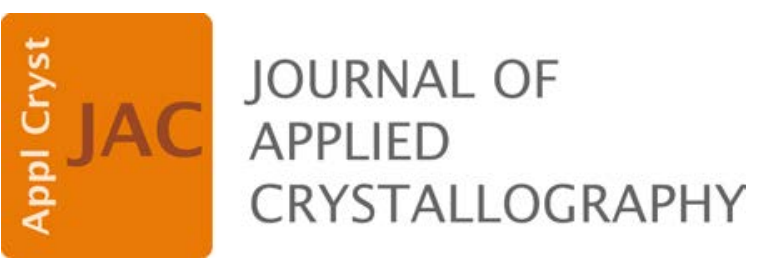

Volume 52 (2019)

Supporting information for article:

Free-film SANS - a novel container-free in situ sample environment with minimized H/D-exchange

Sebastian W. Krauss, Ralf Schweins, Andreas Magerl and Mirijam Zobel 


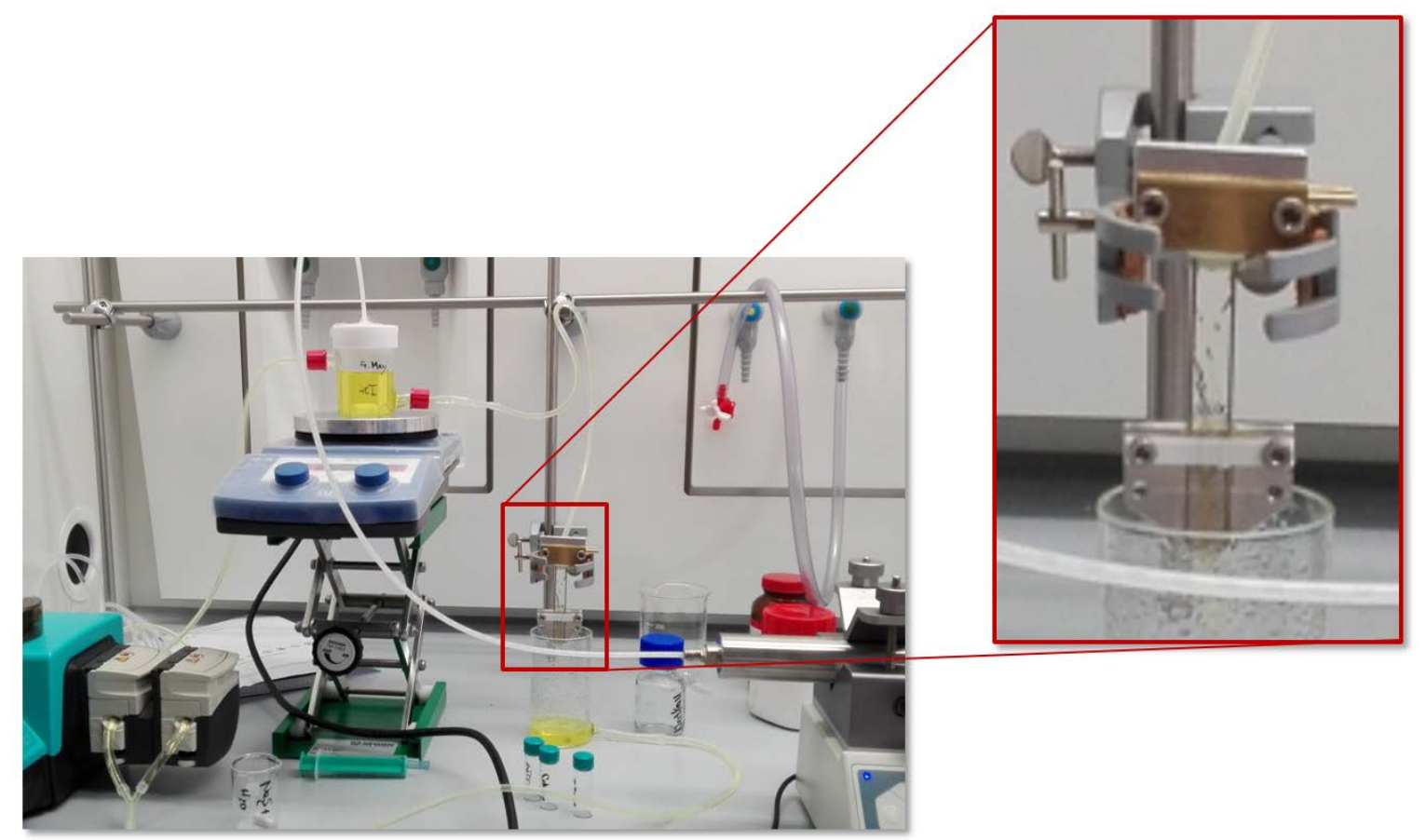

Figure S1 Figure S1 Photograph of the free-film setup in the laboratory, pumping an aqueous CdS nanoparticle suspension for better visibility of the free-film between the wires in the enlarged area.

\section{Figure S2}

Figure S3

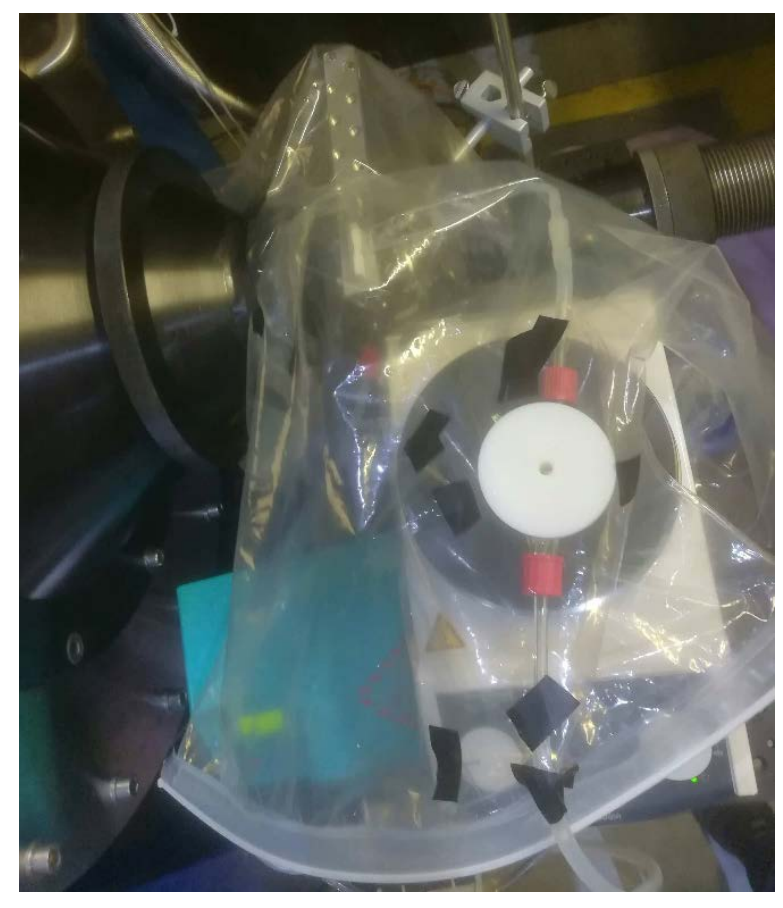

Figure S2 Photograph of the free-film setup at beamline D11 with the Helium bag (top-view) 

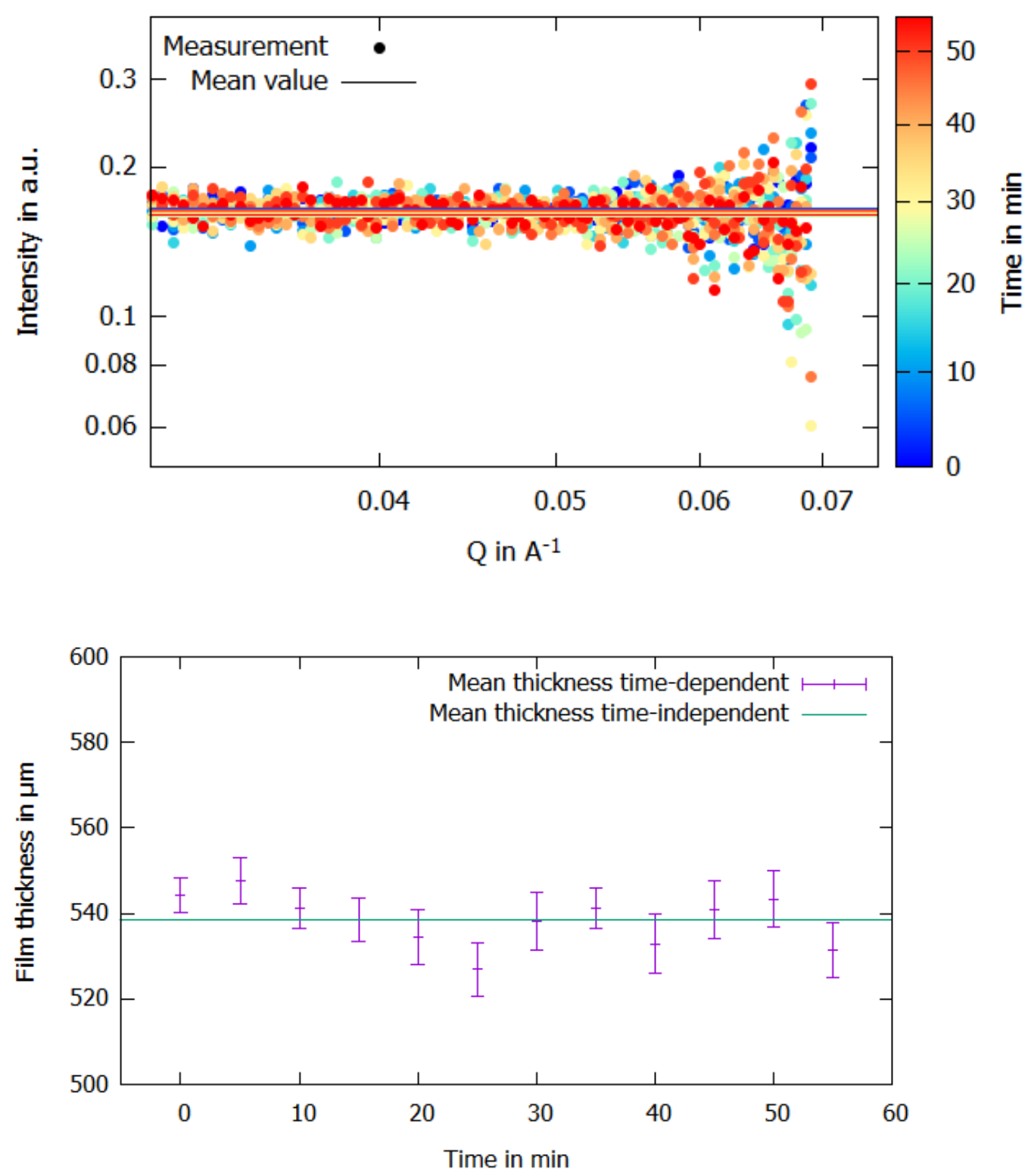

Figure S3 Top: SANS data of D70 for a detector distance of $13 \mathrm{~m}$ over a time of $55 \mathrm{~min}$ in $5 \mathrm{~min}$ intervals together with constants fitted to the individual data sets for an isotopic mixture with $H / D=$ 3/7. Bottom: Film thicknesses as determined from equation (1) showing that the film thickness only slightly fluctuates around the average value. 

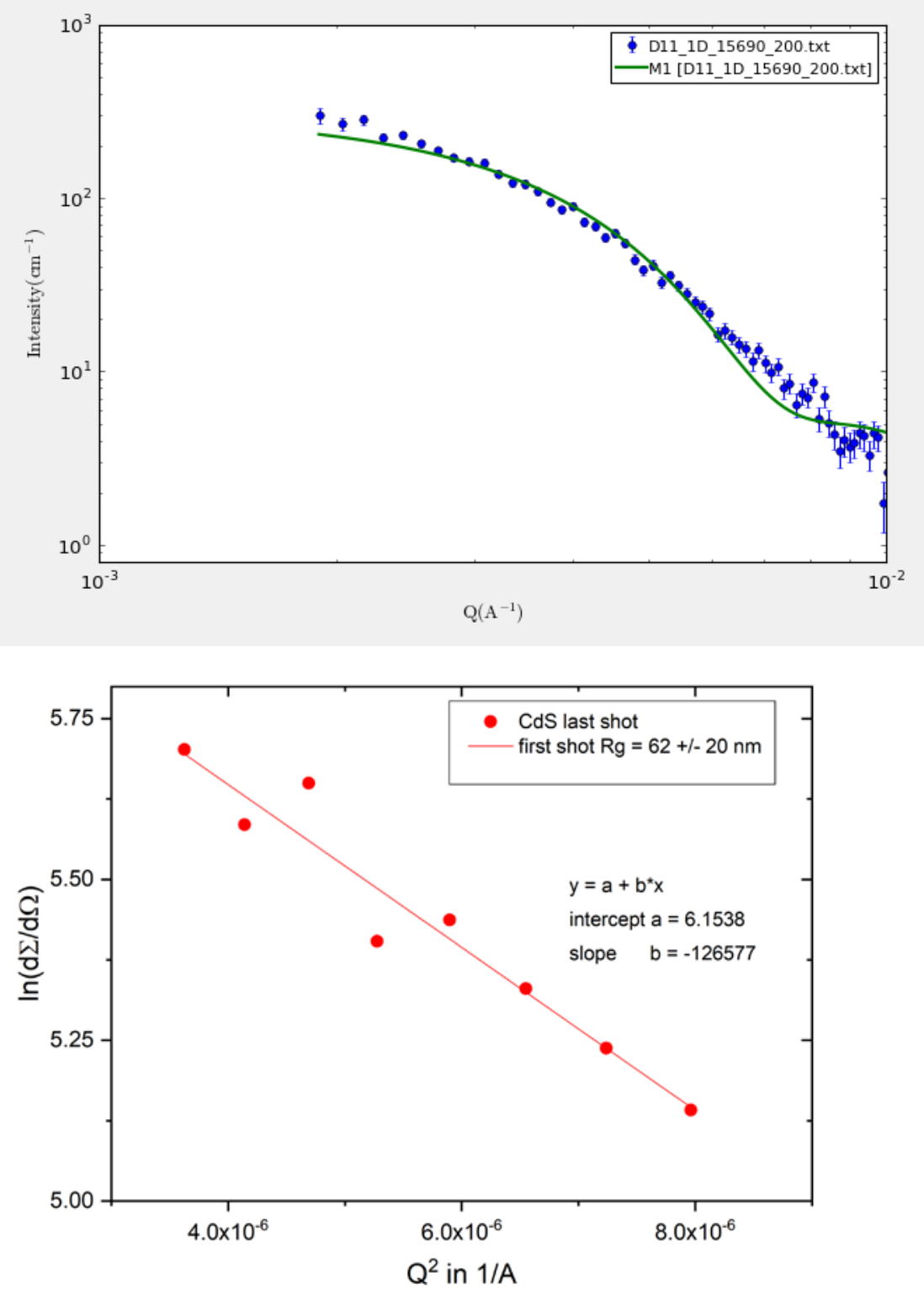

Figure S4 SANS data of EDTA-stabilized CdS nanoparticles in water during the in-situ particle formation of CdS nanoparticles after a reaction time of $190 \mathrm{~min}$ in aqueous solution from $\mathrm{CdCl}_{2}$ and $\mathrm{Na}_{2} \mathrm{~S}$ in presence of EDTA (ethylenediaminetetraacetic acid), all equimolar $\left[\mathrm{Cd}^{2+}\right]=\left[\mathrm{S}^{2-}\right]=[$ EDTA $]$. Top: The solid line represents a fit with a spherical shape factor (preliminary) yielding a radius of $66.2 \mathrm{~nm}+/-0.6 \mathrm{~nm}$. Bottom: Guinier fit resulting in Guinier radius of $62+/-20 \mathrm{~nm}$. 